\title{
PREVALENCE AND CAUSES FOR BLINDNESS AMONG RURAL POPULATION IN COASTAL VILLAGES OF PUDUCHERRY AND TAMILNADU
}

\author{
Loganathan M11, Juliana Rositta Stephen², Sivaranjani S3, Vasudev Anand Rao
}

1 Professor, Department of Ophthalmology, Sri Venkateshwaraa Medical College Hospital and Research Centre.

${ }^{2}$ Assistant Professor, Department of Ophthalmology, Sri Venkateshwaraa Medical College Hospital and Research Centre.

${ }_{3}^{3}$ Assistant Professor, Department of Ophthalmology, Sri Venkateshwaraa Medical College Hospital and Research Centre.

${ }^{4}$ Professor, Department of Ophthalmology, Sri Venkateshwaraa Medical College Hospital and Research Centre.

\begin{tabular}{l}
\hline ABSTRACT \\
OBJECTIVE \\
To identify the common causes for blindness among rural population, and also to know the prevalence of ocular diseases among \\
people in coastal villages.
\end{tabular}

\section{MATERIAL AND METHODS}

Case records of all the free eye camps conducted by Department of Ophthalmology during January 2011 to December 2012 were collected. Demographic data, vision and clinical diagnosis were entered and analysed.

DESIGN- Retrospective analytical study.

RESULTS

Blindness due to cataract is $66.79 \%$, refractive error $21.67 \%$, Pterygium $3.09 \%$ and other causes $8.45 \%$.

\section{CONCLUSION}

Cataract and refractive error are the leading causes for blindness in coastal villages.

\section{KEYWORDS}

Cataract, Refractive Error, Pterygium, Blindness, Coastal Villages.

HOW TO CITE THIS ARTICLE: Loganathan M, Stephen JR, Sivaranjani S, et al. Prevalence and causes for blindness among rural population in coastal villages of Puducherry and Tamilnadu. J. Evolution Med. Dent. Sci. 2016;5(77):5738-5740, DOI: $10.14260 /$ jemds/2016/1293

\section{INTRODUCTION}

Blindness is one of the physical conditions with emotional and economic implications. It affects not only the individual person suffering from blindness, but also the family members and indirectly the community also. Blindness apart from affecting the day-to-day activities of the persons suffering from blindness, it indirectly results in economic loss to the society. Approximately, 45 million people are blind all over the world according to WHO criteria for blindness and around 135 million people are visually disabled. The distribution of blindness varies from different parts of the world, $90 \%$ of the blind as well as visually disabled people are living in developing countries. This variation is mainly due to accessibility and availability of quality healthcare and effective implementation of preventive health programme. Other factors like growing population and ageing contributes to blindness due to cataract and age related diseases.

Blindness is defined according to World Health Organisation (WHO).[1] Best Corrected Visual Acuity (BCVA) in the better eye of $<3 / 60$ or visual fields $<10^{\circ}$. In India according to National Programme for Control of Blindness

Financial or Other, Competing Interest: None.

Submission 18-07-2016, Peer Review 11-08-2016,

Acceptance 17-08-2016, Published 26-09-2016.

Corresponding Author:

Dr. Loganathan $M$,

Department of Ophthalmology,

Sri Venkateshwaraa Medical College Hospital

and Research Centre, Ariyur,

Puducherry-605102.

E-mail: log_smith@yahoo.com

DOI: $10.14260 /$ jemds/2016/1293

\section{(c) (1) $(9)$}

(NPCB), blindness is defined as visual acuity $<6 / 60$ or visual fields $<20^{\circ}$. Both in developed as well as developing countries, cataract remains the single leading cause for blindness. ${ }^{[2]}$ Globally major causes for blindness in order of frequency are cataract, glaucoma, trachoma, vitamin A deficiency, onchocerciasis and others (Diabetic retinopathy, macular degeneration, optic neuropathy, trauma etc.,) Blindness due to these causes can be prevented or treated by measures such as vitamin A supplementation, trachoma prophylaxis with 1\% tetracycline eye ointment. Treating diseases like cataract, trauma, refractive error and screening for glaucoma, diabetic retinopathy will reduce the blindness.

Even though the number of cataract surgeries was increased, cataract remains the single leading cause for blindness. This is mainly due to lack of awareness, fear among people in rural areas and distribution of health care system in rural and urban areas. In recent years there are significant changes in the causes for blindness, ${ }^{[3]}$ such as diabetic retinopathy, ${ }^{[4]}$ glaucoma ${ }^{[5]}$ and trauma.

Corneal blindness ${ }^{[5]}$ was responsible for significant number of blindness. Awareness about eye donation and facilities for keratoplasty to be available in rural areas also to reduce the blindness due to corneal diseases. Sound knowledge of the epidemiological data is necessary to develop strategies for the prevention of preventable blindness. The global effort taken by VISION 2020: The Right to Sight initiative to eliminate the avoidable blindness. It necessitates regular surveys to assess the prevalence of avoidable blindness and planning strategies to implement the preventive measures effectively. Hence, we undertook this study to assess the prevalence and causes for blindness among rural population in coastal villages of Puducherry and Tamil Nadu. 


\section{MATERIALS AND METHODS}

All the case records from the free eye camps conducted by the Department of Ophthalmology for two years (2011-2012) period were collected. In the case records, patient demographic data like age, sex and place were noted. Patient ocular complaints, ocular history and relevant systemic history recorded. Visual acuity was measured by using Snellen's distant visual acuity chart and pin hole. Intraocular pressure by Schiotz indentation tonometry. Routine ocular examination and fundus examination by direct ophthalmoscope were noted during camp. Refractive error screened by using auto refractometer and in some cases manual streak retinoscopy. The findings from each case record were entered in excel sheet and analysed retrospectively. Both male and female in all age group were included in this study. Patients presented with normal visual acuity and only present with near vision problem were excluded from the study. Special investigations like Humphrey visual fields, ultrasound B-scan, Electroretinogram (ERG) and Computerised Tomography (CT-Scan) were done for necessary cases. National Programme for Control Blindness (NPCB) guidelines for blindness was used as criteria for blindness.

\section{Statistics}

Retrospective analytical study.

\section{RESULTS}

Totally 15,783 were analysed. Of these 4615 patients were excluded from the study, because their presentation did not fit with NPCB guidelines for blindness. Finally, 11,168 patients were included in this study. Of the total 11,168 patients with blindness, 6456 were males and 4712 were females. Cataract $66.79 \%$, refractive error - $21.67 \%$, post-op complication $2.09 \%$, corneal cause $-1.47 \%$, glaucoma $-1.21 \%$, DR $-1.47 \%$, pterygium $-3.09 \%$, others $-11.53 \%$.

\begin{tabular}{|c|c|c|}
\hline Diseases & $\begin{array}{c}\text { Number of } \\
\text { Patients }\end{array}$ & Percentage \\
\hline Cataract & 7460 & $66.79 \%$ \\
\hline Refractive error & 2420 & $21.67 \%$ \\
\hline Pterygium & 346 & $3.09 \%$ \\
\hline Post-op complications & 234 & $2.09 \%$ \\
\hline Corneal blindness & 164 & $1.47 \%$ \\
\hline $\begin{array}{c}\text { Posterior segment } \\
\text { pathology }\end{array}$ & 160 & $1.43 \%$ \\
\hline Glaucoma & 136 & $1.21 \%$ \\
\hline Trauma & 132 & $1.18 \%$ \\
\hline $\begin{array}{c}\text { Others (Congenital } \\
\text { anomalies, squint, } \\
\text { nutritional \& tumours) }\end{array}$ & 116 & $1.03 \%$ \\
\hline Total & $\mathbf{1 1 1 6 8}$ & $\mathbf{1 0 0 \%}$ \\
\hline
\end{tabular}

\section{DISCUSSION}

Causes of blindness differs in different parts of the country as well as different parts of the world due to various reasons. This is due to availability of healthcare facilities, its utilisation by public and awareness about preventable blindness. In adults, cataract remains the leading cause for blindness in all over the world. The present study shows majority of the blindness in the coastal villages was due to cataract and uncorrected refractive errors. This finding correlates with NPCB survey conducted in 2001-02. In India, blindness due to cataract is enormous because of the increasing trend of ageing population leading to increase in the new cases of cataract blindness.[6] In recent days percentage of blindness due to cataract reduced significantly; this is mainly due to increased cataract surgical rate, awareness about cataract and its outcome, participation of non-governmental organisations. But cataract remains the single major cause for blindness in developing countries like India.

Apart from cataract, the other causes for preventable and treatable blindness include postoperative complications like bullous keratopathy, posterior capsule opacification endophthalmitis etc., corneal blindness,[7] glaucoma, trauma and posterior segment pathology like Diabetic Retinopathy (DR). In children and young adults, refractive error ${ }^{[8]}$ accounts for majority of the blindness. Glaucoma has now become the second leading cause of blindness in both developing and developed world. The Eleventh plan of NPCB emphasises screening for DR in both insulin and non-insulin dependent diabetic individuals. It also emphasises the significance of screening for glaucoma by means of measuring intraocular pressure and glaucomatous optic disc changes by fundus examination in patients above 35 years of age attending ophthalmology outpatient department.[9]

In our study, refractive errors accounted for $21.67 \%$ which is higher than that reported by NPCB. Uncorrected refractive errors have been recently identified as one of the major ocular public health problem. Hence, it has been recognised as one of the priorities under VISION 2020 initiative. Other diseases given priorities globally under vision 2020 are cataract, trachoma, childhood blindness and onchocerciasis. In India in addition to this diabetic retinopathy, glaucoma and corneal blindness were also given priorities. These diseases have been added in VISION 2020, because of their prevalence in India and it affects the vision significantly in both urban and rural population. These can be identified and corrected in early life to prevent ametropic amblyopia through special eye camps or as a part of school health screening programmes. The epidemiology of corneal blindness includes a variety of infectious and inflammatory conditions causing corneal scarring. Trachoma, ocular trauma and infectious keratitis are the important causes for corneal blindness, especially monocular blindness. But, more often these cases are underreported.

Ocular trauma is one of the important causes of unilateral blindness and a major cause of ocular morbidity among young adult population. This is due to workplace injuries like chemical injuries, especially those who are working in chemical industries and their outdoor activities related physical trauma like stick and stone injuries. It can be prevented by simple measures like wearing protective goggles and immediate first aid measures such as copious irrigation with normal saline or clean water. Though majority of them are unilateral, it provides a significant proportion of people in productive age group with only one eye for the rest of their lifetime. Health promotion regarding the benefits of protective eye wear should be undertaken and strictly followed. Policy level changes regarding the mandatory use of protective measures should be regarded.

Our study reflects cataract and uncorrected refractive errors as the major causes of blindness, which can be efficaciously treated. The prevalence of Pterygium is significantly higher in our study population compared to previous studies.[10] This may be attributed to the fact that the 
people living in coastal villages are more exposed to ultraviolet radiations and dry sandy climate. Guidelines and diagnostic criteria[11] should be available for the screening of preventable blindness caused by glaucoma, DR and ocular trauma. Inadequate knowledge about ocular health, poor accessibility and utilisation of health care services are the important factors for the increased prevalence of preventable blindness in developing countries.

The limitations of our study are age, gender; occupation and socio-economic status of the study population were not compared. Still we believe that our study forms a representative sample in evaluating the prevalence of causes of blindness in the coastal villages of Puducherry and Tamil Nadu.

\section{CONCLUSION}

Cataract and refractive errors are the leading causes for blindness. Apart from these, postoperative complications, glaucoma, retinopathy and injuries also contribute to blindness significantly. So early detection and intervention are required not only for cataract but also for glaucoma, DR, postoperative complications, trauma to prevent permanent blindness. Health education regarding the causes, preventive measures and treatment options for the preventable blindness should be done. National programmes should target the elderly population and school children specifically in remote areas to provide quality vision in these group of population. More comprehensive studies should be done to identify the various risk factors and appropriate strategies should be planned to reduce the load of preventable and treatable blindness.

\section{REFERENCES}

1. Resnikoff S, Pascolini D, Etya'aleD, et al. Global data on visual impairment in the year 2002. Bull World Health Organ 2004;82(11):844-51.
2. Minassian DC, Mehra V. 3.8 million blinded by cataract each year: projections from the first epidemiological study of incidence of cataract blindness in India. Br J Ophthalmol 1990;74(6):341-3

3. Khanna RC, Marmamula S, Krishnaiah S, et al. Changing trends in the prevelance of blindness and visual impairment in a rural district of India: systemic observations over a decade. Indian J Ophthalmol 2012;60(5):492-7.

4. Dhingra MK, Jose R, Rathore AS, et al. Global news: prevention of retinopathy. NPCB India 2007;1(4):5-6.

5. Vijaya $\mathrm{L}_{1}$ George $\mathrm{R}$, Arvind $\mathrm{H}$, et al. Prevalence and causes of blindness in the rural population of the Chennai glaucoma study. Br J Ophthalmol 2006;90(4):407-10.

6. Krishnaiah S, Nirmalan PK, Shamanna BR, et al. Ocular trauma in a rural population of southern India: the Andhra Pradesh eye disease study. Ophthalmology 2006;113(7):1159-64.

7. Whitcher JP, Srinivasan M, Upadhyay MP. Corneal blindness: a global perspective. Bull World Health Organ 2001;79(3):214-21.

8. Batra N, Kaushal D, Gill AS. Refractive errors in school children: a review from Punjab. NPCB India 2007;1(4):2-4.

9. Sood NN, Lamba PA, Ratnaraj A, et al. Glaucoma survey in a semiurban community in Pondicherry. Orient Archives of Ophthalmology 1968;6:235-42.

10. Lim CY, Kim SH, Chuck RS, et al. Risk factors for pterygium in Korea: the Korean national health and nutrition examination survey V, 2010-2012. Medicine (Baltimore) 2015;94(32):e1258.

11. Bachani D, Murthy GV, Gupta KS. Rapid assessment of cataract blindness in India. Indian J Public Health 2000;44(3):82-9. 